\title{
Simulation Analysis on Proportional Integral and Derivative Control of Closed Loop DC Motor Drive with Bipolar Voltage Switching
}

\author{
${ }^{1}$ P. Karpagavalli and ${ }^{2}$ A. Ebenezer Jeyakumar \\ ${ }^{1}$ Department of Electrical and Electronics Engineering, Anna University Chennai, Salem, India \\ ${ }^{2}$ Department of Electrical and Electronics Engineering, Anna University Chennai, Coimbatore, India
}

Received 2013-05-30, Revised 2013-06-22; Accepted 2013-06-29

\begin{abstract}
This study presents the performance of a new four quadrant single phase DC drive closed loop system controlled by proportional integral and derivative controller with Pulse Width Modulation (PWM) full bridge DC-DC converter using bipolar voltage switching. The proposed method is found to be more efficient in improving the step response characteristics such as reducing the settling time, rise time, steady state error and maximum overshoot in speed response of the closed loop DC motor drive and also reduced total harmonics distortion in the AC line current when compared to open loop system. The proposed topologies were simulated using MATLAB/Simulink software package and the results were obtained.
\end{abstract}

Keywords: DC Motor, DC-DC Converter, Pulse Width Modulation, PID Controller, Ziegler-Nichols Method, Bipolar Voltage Switching

\section{INTRODUCTION}

Due to its excellent speed control characteristics, the DC motor has been widely used in industry even though its maintenance cost is higher than inducltion motor. Proportional integral and derivative controller has been widely used for speed control. DC Motor drive system with phase controlled gained a high popularity due to their simple implementation, but it has disadvantages due to large value of phase delay angle, which causes reduced input power factor and high harmonic content in the input AC line current in the discontinuous period. Therefore large size reactive components became essential on efficiency, expense of cost and slower current response of the system (Abdelhamid, 2000). Generally, the current through phase controlled converter is unidirectional, while the output voltage can reverse polarity. The two quadrant operation is not suited for DC motor braking with reversible voltage, which requires the voltages unidirectional but the current to be reversible. Therefore, for regenerative braking two back to back connected thyristor converter can be used. It capability is to operate in all the four quadrants. For the same armature inductance, zone of discontinuous conduction operation and the ripple of load current are reduced when compared to phase controlled converters (Kazmierkowski and Malesani, 1998). Uniform pulse width modulation techniques are extensively used in converter circuits due to the simple implementation, of their control circuit and advantages gained from increasing switching frequency (Hamed, 1997). However, this will lead to the increased switching losses. The more availability of high frequency high power switching devices, such as MCT, IGBT and MOSFET are expected to reinforce self-commutated $\mathrm{AC}$ to $\mathrm{DC}$ converters with PID-PWM control techniques to replace the conventional phase-controlled converters within the available power ratings (Hui et al., 2000). In the

Corresponding Author: P. Karpagavalli, Department of Electrical and Electronics Engineering, Anna University Chennai, Salem, India 
literature study (Abdelhamid, 2000; Kazmierkowski and Malesani, 1998; Hamed, 1997), the simulation of closed loop DC drive is not presented hence an attempt is made in this study. In the simulation result the single phase variable DC drives controlled by PID controller has been improved obviously (Lin and Lu, 2000; Al-Mashakeh, 2009; Zhang, 2008; Thomas and Poongod, 2009; Mehra et al., 2010; Montiel et al., 2007; Yu and Hwang, 2004; Hang et al., 1991; Krishnan, 2001). The PID controller parameter values can be obtained using the Ziegler- Nichols method. This study has been organized as follows: Section 2 formulates the system model of a DC motor and how it can be applied to DC motor. In Section 3 the proposed PID-PWM full bridge DC-DC converter is described and detailed circuit diagram of model is shown. In Section 4. PID controller ZieglerNichols method is discussed. In Section 5 describes the switching patterns generated for bipolar voltage switching and the comparison between open loop, closed loop system with the results and performance characteristics of four quadrant operation with bipolar switching MATLAB/Simulink simulation is presented in Section 6. Conclusion is presented in Section 7.

\section{SYSTEM MODEL}

As reference a separately excited DC Motor equivalent circuit is shown in Fig. 1. The current in the field coil and the armature is independent of each other. As a result, these motors have excellent speed control. Hence DC motors are typically used in applications that require five or more horse power. The equations describing the dynamic behavior of the DC motor are as follows Equation 1-4:

$$
\begin{aligned}
& \mathrm{V}=\mathrm{R}_{\mathrm{a}} \mathrm{i}_{\mathrm{a}}+\mathrm{L}_{\mathrm{a}} \frac{\mathrm{di}_{\mathrm{a}}}{\mathrm{dt}}+\mathrm{e}_{\mathrm{b}} \\
& \mathrm{T}_{\mathrm{m}}=\mathrm{K}_{\mathrm{t}} \mathrm{i}_{\mathrm{a}}(\mathrm{t}) \\
& \mathrm{T}_{\mathrm{m}}=\mathrm{J} \frac{\mathrm{d}^{2} \omega(\mathrm{t})}{\mathrm{dt}^{2}}+\mathrm{B} \frac{\mathrm{d} \omega(\mathrm{t})}{\mathrm{dt}} \\
& \mathrm{e}_{\mathrm{b}}=\mathrm{e}_{\mathrm{b}}(\mathrm{t})=\mathrm{K}_{\mathrm{b}} \frac{\mathrm{d} \omega(\mathrm{t})}{\mathrm{dt}}
\end{aligned}
$$

Simplification and taking the ratio of $\omega(s) / v(s)$ we will get the transfer function as below Equation 5:

$$
\frac{\omega(s)}{V_{a}(s)}=\frac{K_{b}}{\left[L_{a} S^{2}+\left(R_{a} J+B L_{a}\right) S+\left(K_{b}^{2}+R_{a}\right)\right]}
$$

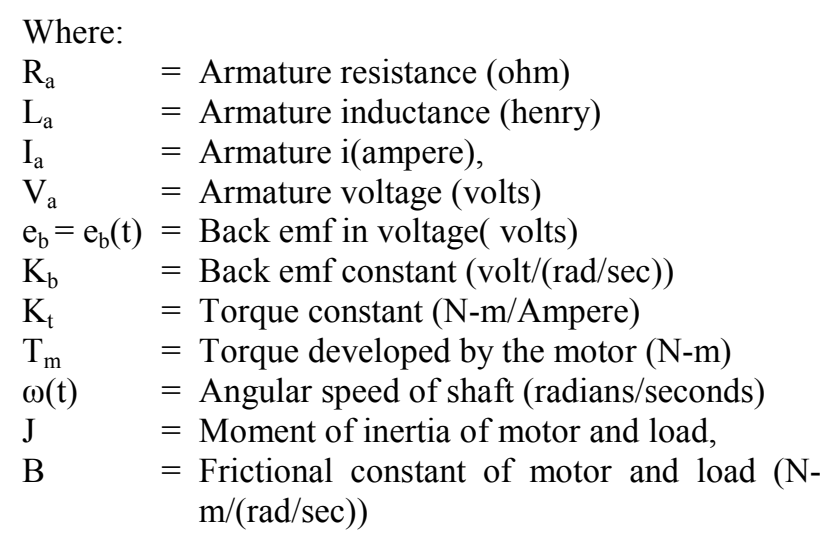

\subsection{Numerical Values}

The DC motor under study has the following specification and parameters:

- $\quad$ Specifications

$5 \mathrm{hp}, 240$ volts, 16 amps, $1500 \mathrm{rpm}$

- Parameters

$\mathrm{R}_{\mathrm{a}}=0.50 \mathrm{hm}, \quad \mathrm{L}_{\mathrm{a}}=0.01 \mathrm{H}, \quad \mathrm{K}_{\mathrm{b}}=1.02$ volts $/(\mathrm{rad} / \mathrm{sec}) \mathrm{J}=0.05 \mathrm{~kg}-\mathrm{m}^{2} / \mathrm{rad}, \mathrm{B}=0.02 \mathrm{~N}$ $\mathrm{m} / \mathrm{rad} / \mathrm{sec}$ )

The overall transfer function of the DC motor is given below Equation 6:

$$
\frac{\omega(\mathrm{s})}{\mathrm{v}(\mathrm{s})}=\frac{0.05}{0.000000375 \mathrm{~S}^{2}+0.000215 \mathrm{~S}+0.00255}
$$

\section{PROPOSED PID-PWM FULL BRIDGE DC-DC CONVERTER}

The block diagram of the proposed single phase DC drive system is shown in Fig. $\mathbf{2}$ and detailed circuit diagram of diode rectifier, DC-DC converter and DC motor are shown in Fig. 3.

The single phase ac supply applied to a diode rectifier and a LC filter with braking resistor, such that a constant amplitude dc link voltage is estabilized. DC motor load is powered through full bridge DC-DC converter which consists of four MOSFET switches $\left(\mathrm{M}_{1}, \mathrm{M}_{2}, \mathrm{M}_{3}\right.$ and $\left.\mathrm{M}_{4}\right)$ and their respective anti-parallel diodes $\left(D_{1}, D_{2}, D_{3}\right.$ and $\mathrm{D}_{4}$ ), these switches are controlled by PWM technique with PID controller. The diagonally opposite switches $\mathrm{M}_{1}, \mathrm{M}_{4}$ and $\mathrm{M}_{2}, \mathrm{M}_{3}$ are treated as two switch pairs where pair of switches is turn on and off simultaneously such that the motor voltage is of a bipolar nature. 
P. Karpagavalli and A. Ebenezer Jeyakumar / American Journal of Applied Sciences 10 (7): 714-723, 2013

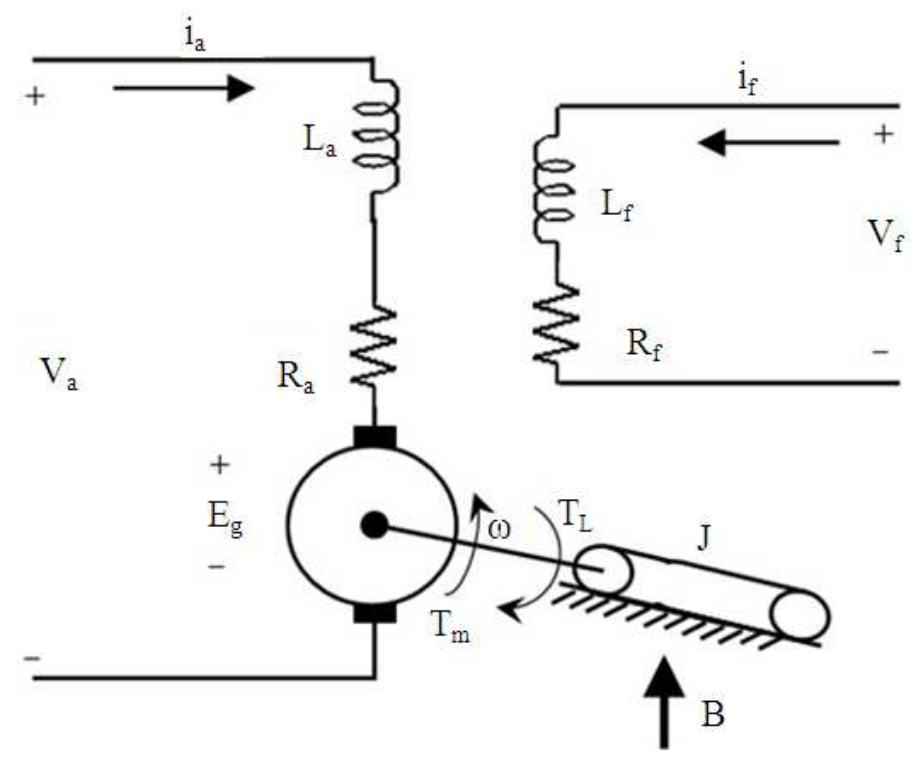

Fig. 1. Equivalent circuit of separately excited DC motor

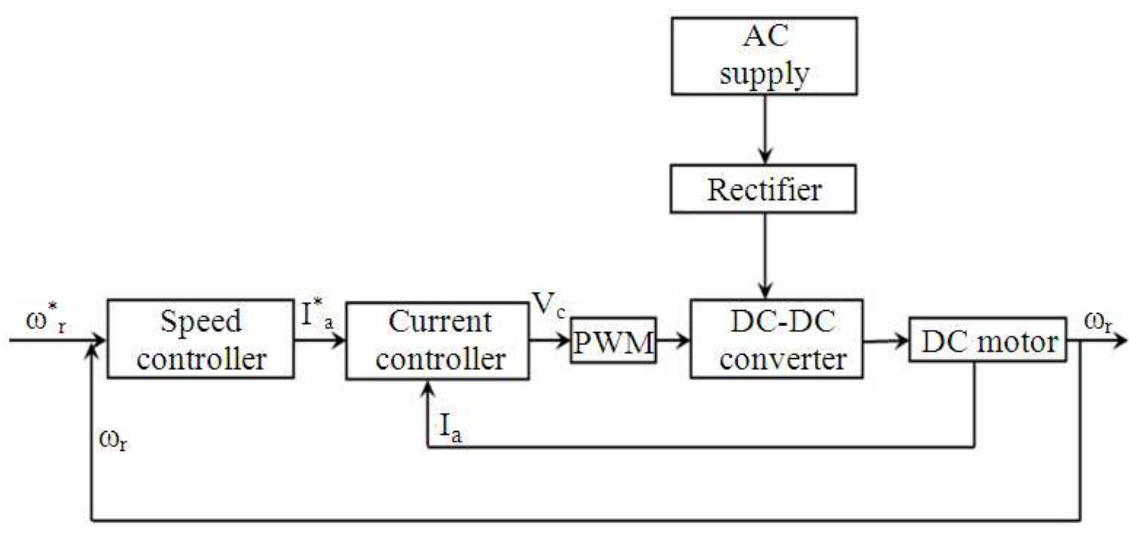

Fig. 2. Block diagram of PID-PWM full bridge DC-DC converter

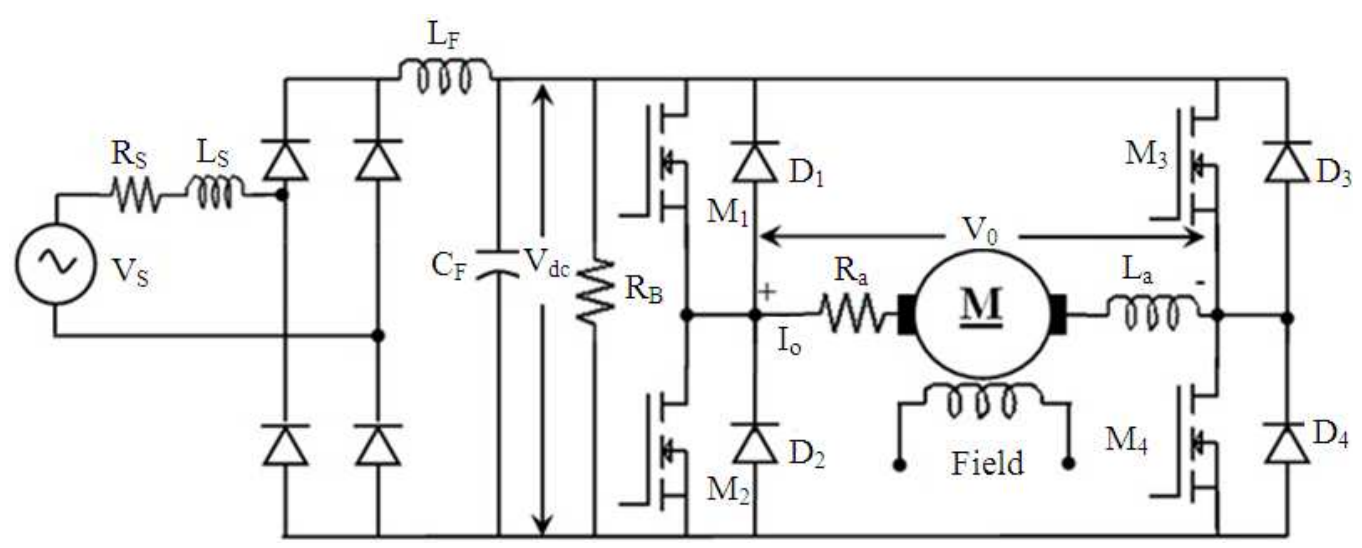

Fig. 3. Circuit diagram of PID-PWM full bridge DC-DC converter 
Conventional PID controller is used as a speed controller for recovering the actual motor speed to the reference. The reference and measured speed are the input signals to the PID controller. The $\mathrm{K}_{\mathrm{P}}, \mathrm{K}_{\mathrm{I}}$ and $\mathrm{K}_{\mathrm{D}}$ values of controller are determined by Ziegler-Nichols methods. The controller output is limited to give the reference signals for one input of current controller and other one as measured current. The current error amplified through this controller is emerged as a control voltage $\left(\mathrm{V}_{\mathrm{c}}\right)$. This control voltage $\left(\mathrm{V}_{\mathrm{c}}\right)$ is limited and compared with a triangular signal, to generate PWM pulses to MOSFET switches.

\section{PID CONTROLLER: ZIEGLER- ZIGLER}

The control system performs poor characteristics and even it becomes unstable, if improper values of the controller tuning constants are used. So it becomes necessary to tune the controller parameters to achieve good control performance with the proper choice of tuning constants. Controller tuning involves the selection of the best values of $K_{c}, T_{I}$ and $T_{D}$. This is often a subjective procedure and is certainly process dependent. It is widely accepted and straightforward method for tuning the PID controller. First, the controller is set to $\mathrm{P}$ mode only. The gain of the controller $\left(\mathrm{K}_{\mathrm{c}}\right)$ is set to a small value. A small set point change is made and the response of the controlled variable is observed. If $\mathrm{K}_{\mathrm{c}}$ is low the response will be sluggish. Increasing $\mathrm{K}_{\mathrm{c}}$ by a factor of two and making another small change in the set point or the load is preceded until the response becomes oscillatory. Finally, $\mathrm{K}_{\mathrm{c}}$ is adjusted until a response is obtained that produces continuous oscillations. This is known as the ultimate gain $\left(\mathrm{K}_{\mathrm{u}}\right)$. The period of the oscillations $\left(T_{u}\right)$ is shown in Fig. 4. The procedure of the method includes to set the integral and derivative coefficients to zero and increasing the proportional coefficient gradually from 0 till the system just begins to oscillate continuously. The proportional coefficient at this point is called the ultimate gain $K_{u}$ and the period of oscillation at this point is called ultimate period $\mathrm{T}_{\mathrm{u}}$. The controller settings are then obtained from the following Table 1.

\section{CLOSED LOOP CONTROL OF DC DRIVE WITH BIPOLAR VOLTAGE SWITCHING}

In practical DC motor drive system it is required to operate the drive at a constant torque or constant power with controlled acceleration and deceleration. Most of the industrial drives operates in closed loop control system has advantages like fast dynamic response, reduced effect of load disturbances and improved accuracy.

The proposed PID-PWM technique is established by comparing a carrier triangular wave $\left(\mathrm{V}_{\text {tri }}\right)$ at relatively high frequency $\left(f_{c}\right)$ with control voltage $V_{c}$ ie output of the current PID controller. The switching frequency of carrier triangular wave is $1 \mathrm{khz}$. The switching patterns are generated in such a way that when $V_{c}>V_{\text {tri, }}$, switch $M_{1}$ and $\mathrm{M}_{4}$ are turn on otherwise, $\mathrm{M}_{2}$ and $\mathrm{M}_{3}$ are turn on. The switching patterns are shown in Fig. 5.

The duty cycle $\left(\alpha_{1}\right.$ and $\left.\alpha_{2}\right)$ of the switch pairs are given by Equation 7 and 8 :

$$
\begin{aligned}
& \alpha_{1}=0.5\left(1+\frac{\mathrm{v}_{\mathrm{c}}}{\mathrm{v}_{\text {tri }}}\right) \\
& \alpha_{2}=1-\alpha_{1}
\end{aligned}
$$

Therefore, the converter output voltage $\mathrm{V}_{\mathrm{o}}$ is given by Equation 9 and 10:

$$
\begin{aligned}
& \mathrm{V}_{\mathrm{o}}=\alpha_{1} \mathrm{v}_{\mathrm{dc}}-\alpha_{2} \mathrm{v}_{\mathrm{dc}} \\
& =\left(2 \alpha_{1}-1\right) \mathrm{v}_{\mathrm{dc}}
\end{aligned}
$$

Substituting by $\alpha_{1}$ from Equation 7 yields Equation 11 and 12:

$$
\begin{aligned}
& \mathrm{V}_{\mathrm{o}}=\frac{\mathrm{v}_{\mathrm{C}}}{\mathrm{v}_{\mathrm{tri}}} \mathrm{v}_{\mathrm{dc}} \\
& \mathrm{V}_{\mathrm{o}}=\mathrm{kv}_{\mathrm{dc}}
\end{aligned}
$$

Where:

$$
\mathrm{k}=\frac{\mathrm{v}_{\mathrm{C}}}{\mathrm{v}_{\text {tri }}}
$$

Powering mode and Regenerative modes of operation are obtained. In powering mode the motor current is carried by either switch pairs $\mathrm{M}_{1}, \mathrm{M}_{4}$ or $\mathrm{M}_{2}, \mathrm{M}_{3}$ according to the polarity of the motor voltage. The energy stored in the reactive element is returned back to the supply through either diode pairs $D_{1}, D_{4}$ or $D_{2}, D_{3}$. in the regenerative mode. 


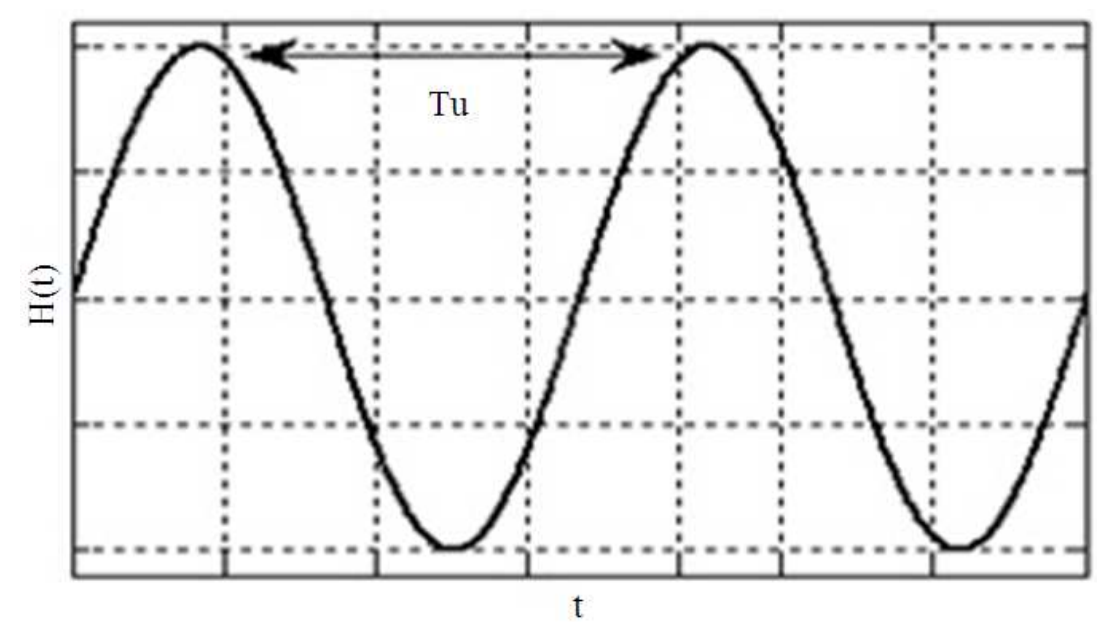

Fig. 4. Steady oscillation illustrating the ultimate period

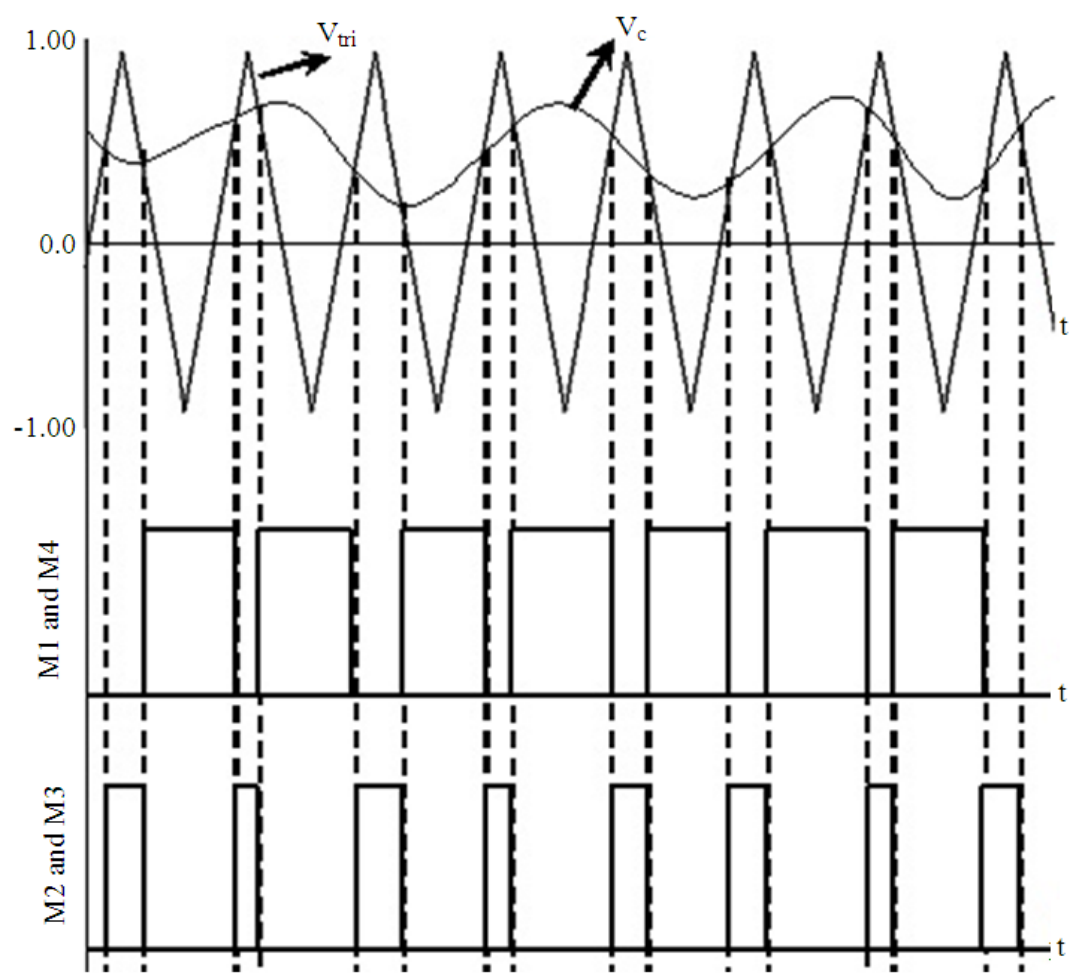

Fig. 5. Switching patterns of bipolar voltage switching

\section{SIMULATION RESULTS AND DISCUSSION}

The simulation of the single phase D.C motor drive system controlled by PID-PWM with full bridge DCDC converter was done using the software package
MATLAB/SIMULINK. The simulink model of proposed PID-PWM full bridge DC-DC converter is illustrated in Fig. 6 and also PID gains calculated in Table 1 was performed using MATLAB. The calculated gains of PID controller are provided in Table 2. 
P. Karpagavalli and A. Ebenezer Jeyakumar / American Journal of Applied Sciences 10 (7): 714-723, 2013

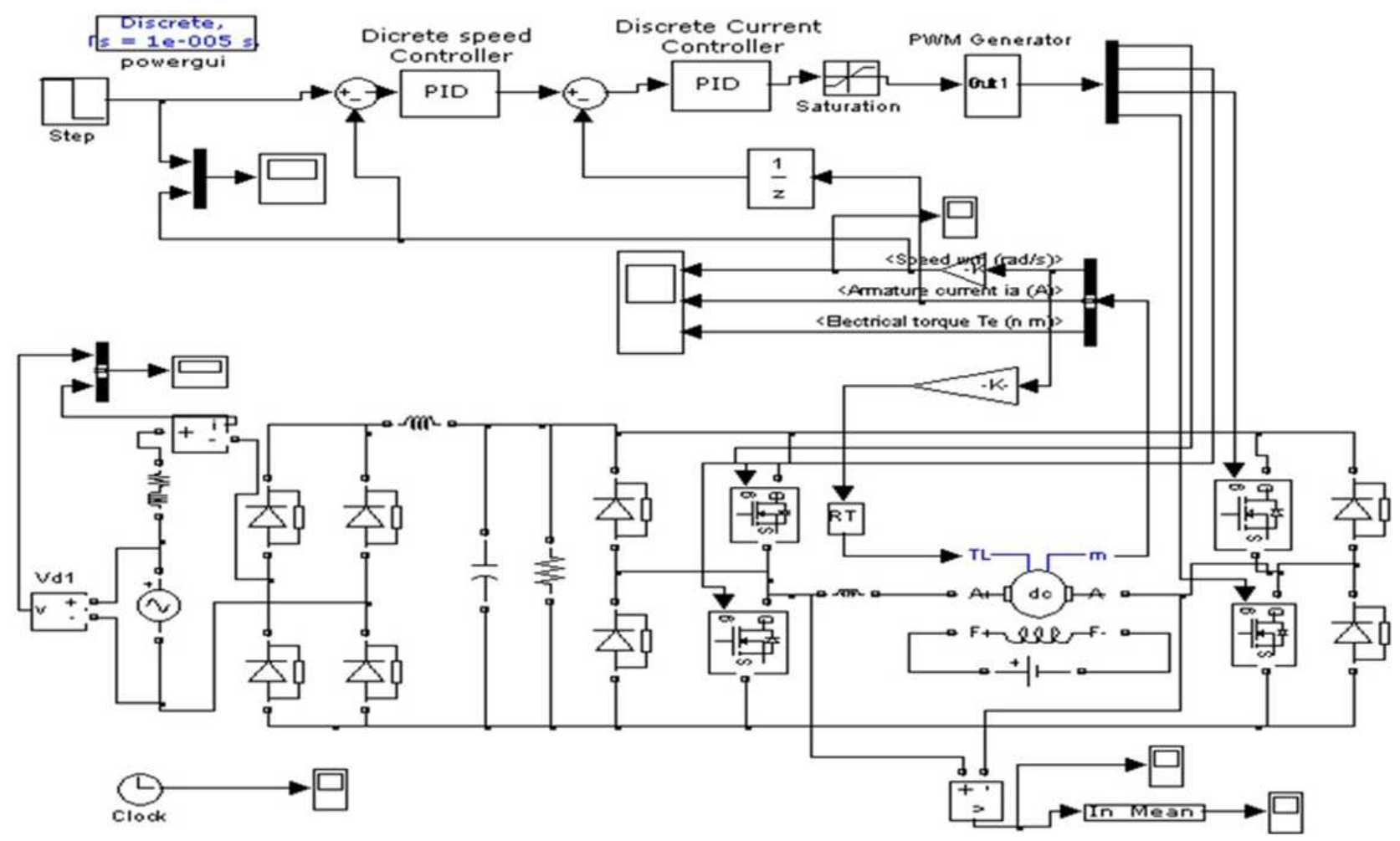

Fig. 6. Simulink model of proposed PID-PWM full bridge DC-DC converter

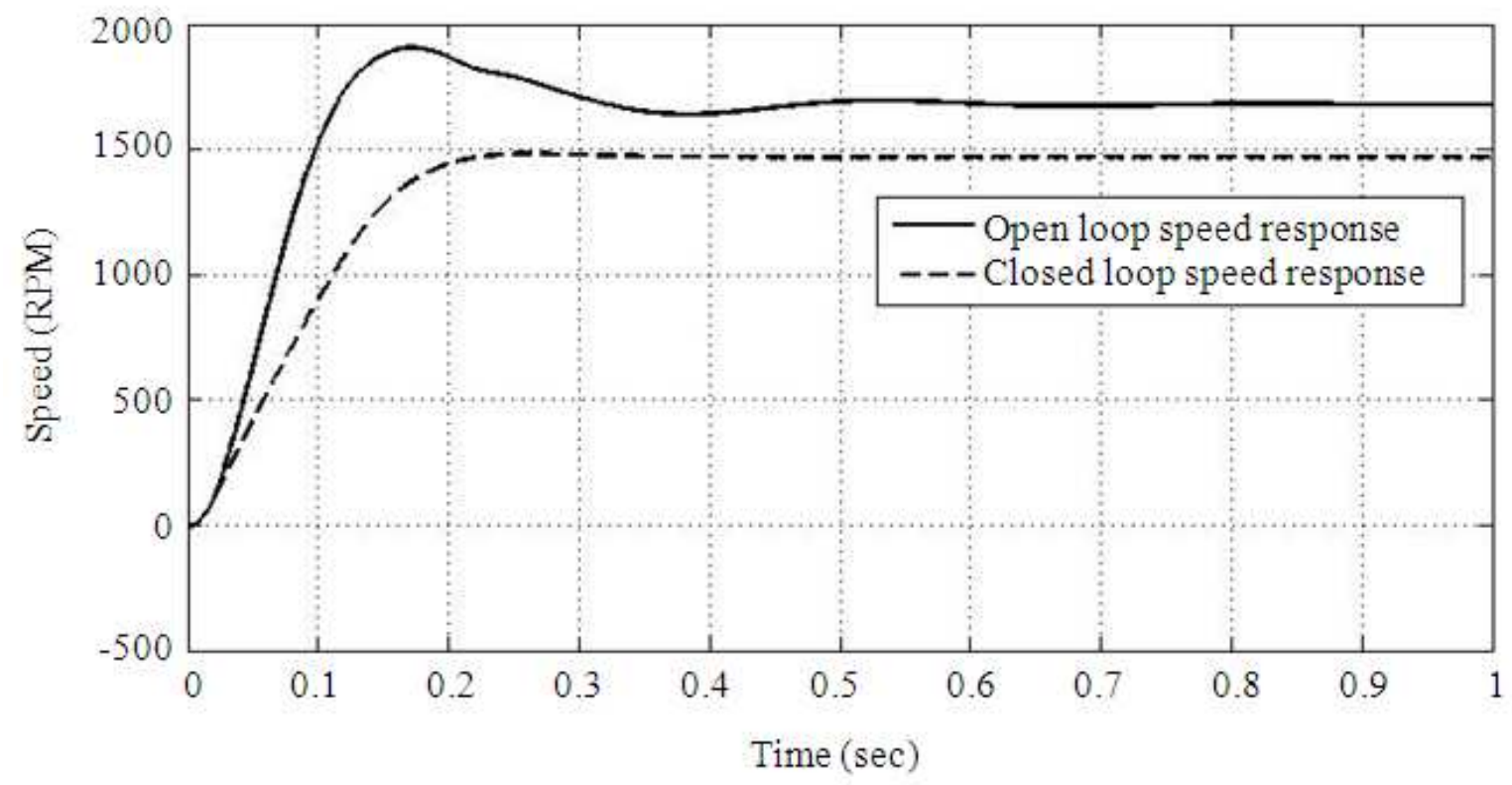

Fig. 7. Open loop and closed loop speed response DC motor 
P. Karpagavalli and A. Ebenezer Jeyakumar / American Journal of Applied Sciences 10 (7): 714-723, 2013

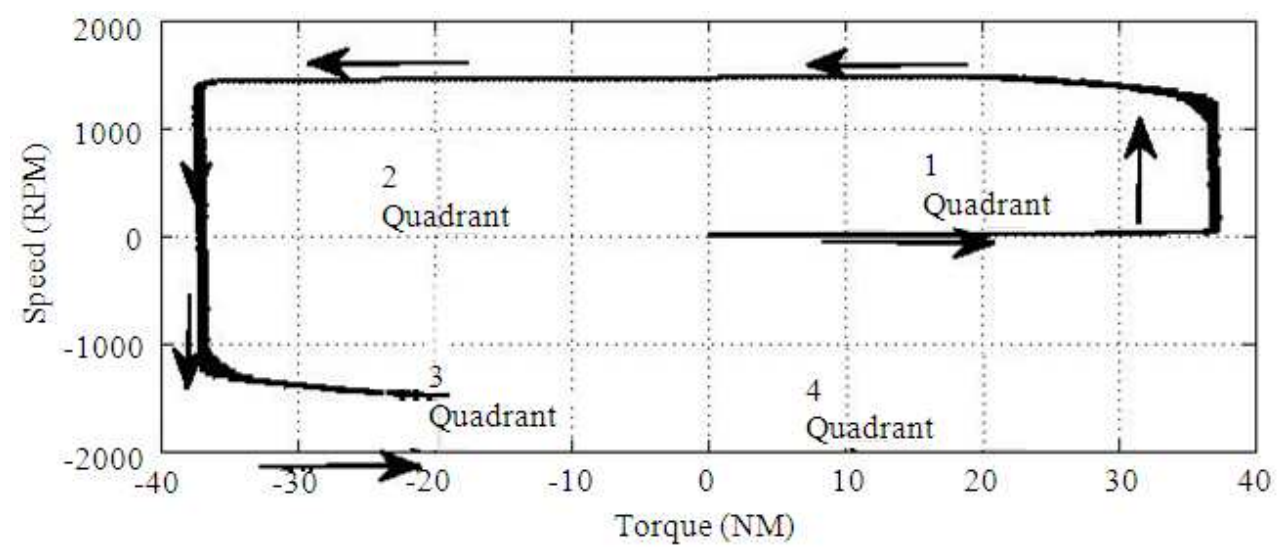

Fig. 8. Torque-speed characteristics (four quadrant)

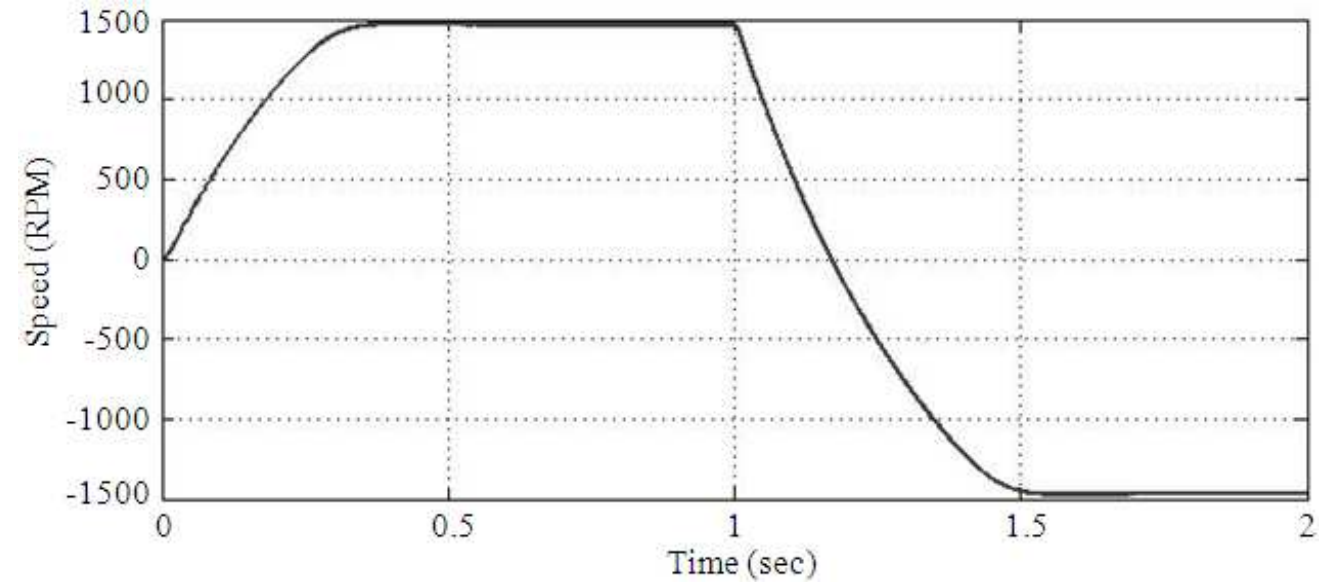

Fig. 9. Speed response (four quadrant)

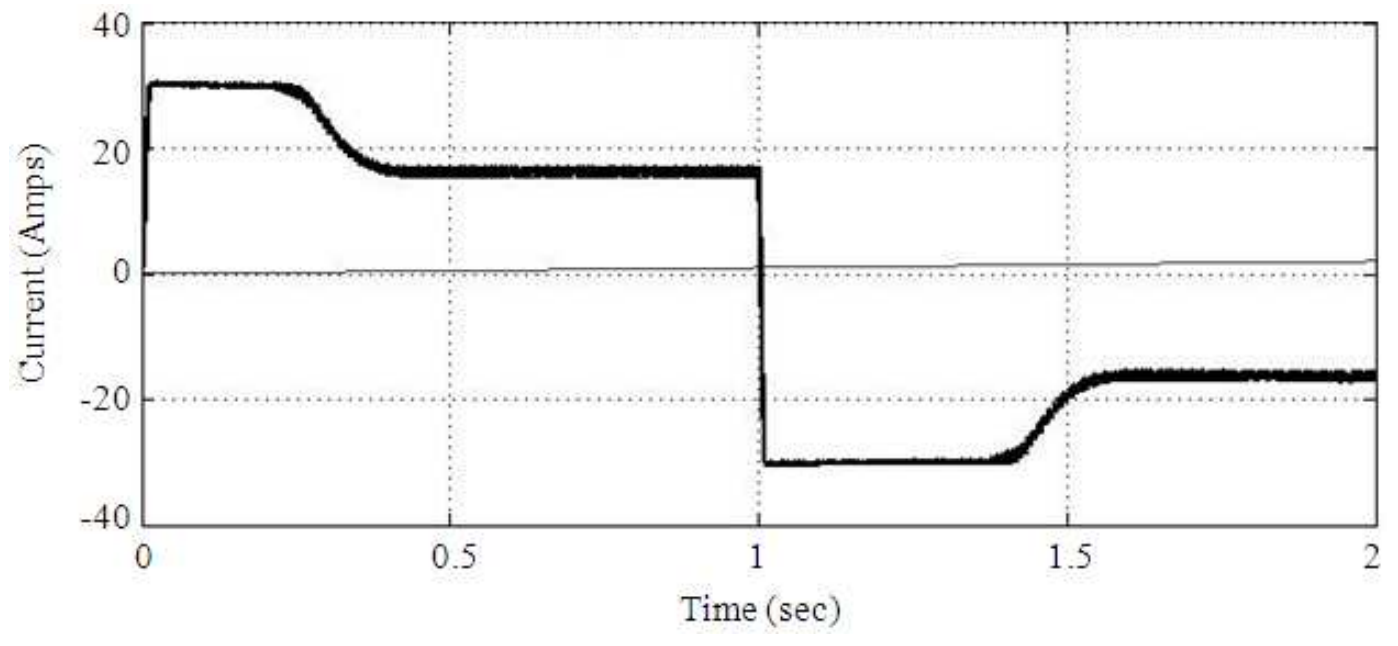

Fig. 10. Load current (four quadrant) 
P. Karpagavalli and A. Ebenezer Jeyakumar / American Journal of Applied Sciences 10 (7): 714-723, 2013

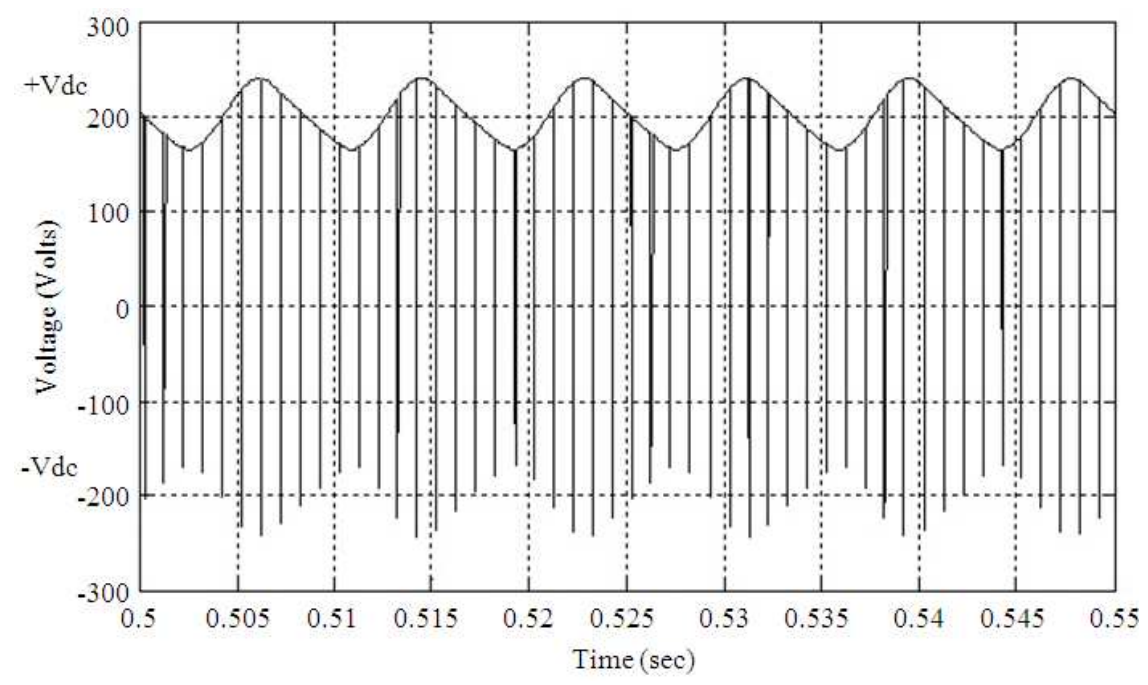

Fig. 11. Load voltage-forward motoring motor

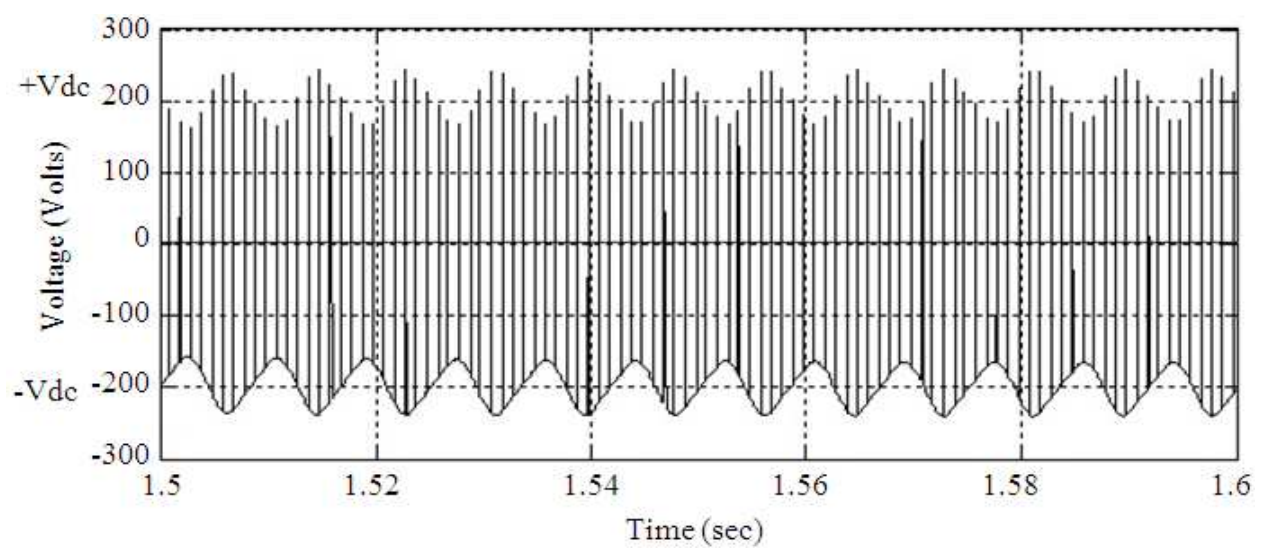

Fig. 12. Load voltage-reverse motoring mode

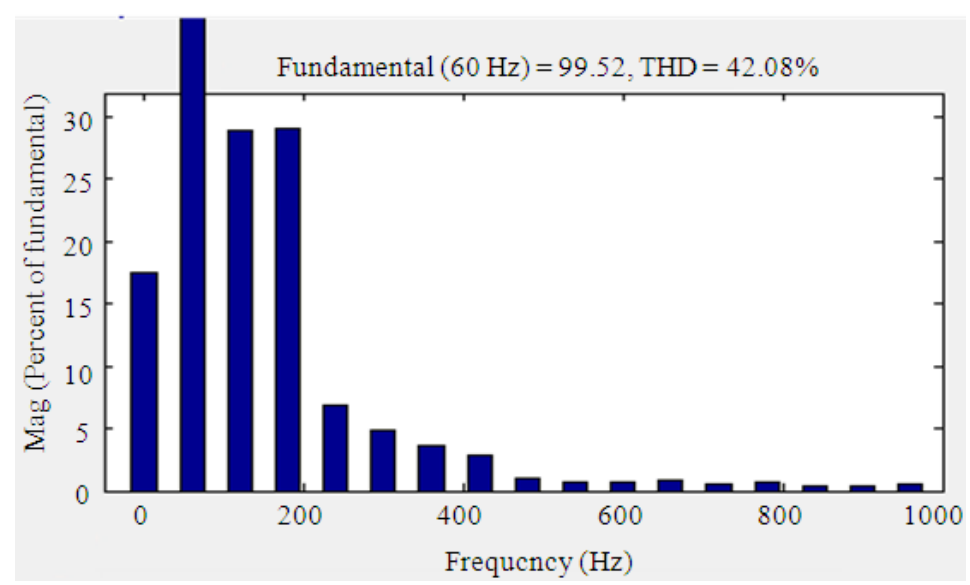

Fig. 13. FFT analysis for closed loop system 


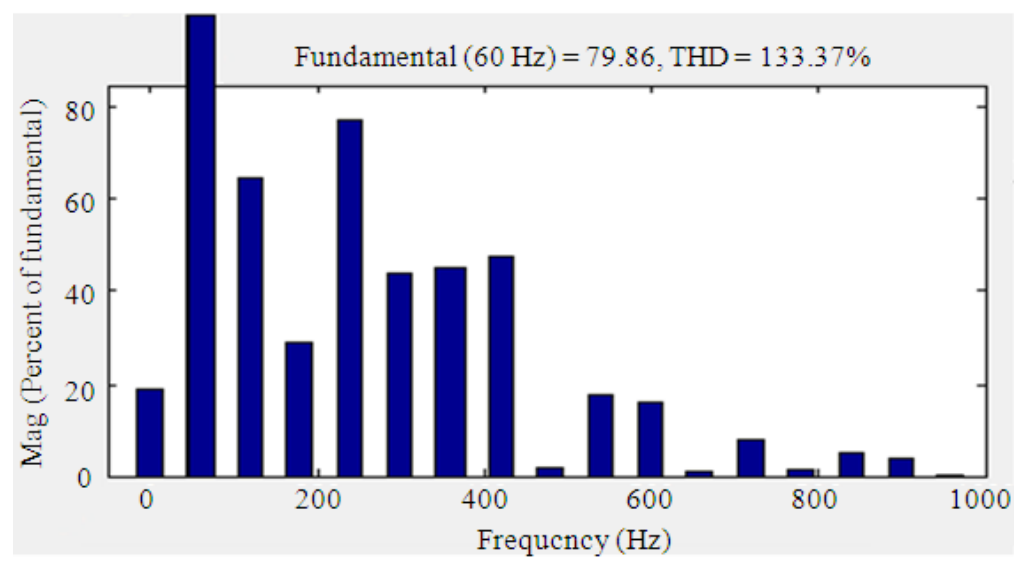

Fig. 14. FFT analysis for open loop system

Table 1. Tuning parameters for Ziegler-Nichols closed loop ultimate gain method

\begin{tabular}{llll}
\hline Controller & $\mathrm{K}_{\mathrm{P}}$ & $\mathrm{K}_{\mathrm{I}}$ & $\mathrm{K}_{\mathrm{D}}$ \\
\hline $\mathrm{P}$ & $0.50 * \mathrm{~K}_{\mathrm{u}}$ & & \\
PI & $0.45 * \mathrm{~K}_{\mathrm{u}}$ & $1.2 / \mathrm{T}_{\mathrm{u}}$ & \\
PID & $0.60 * \mathrm{~K}_{\mathrm{u}}$ & $2 / \mathrm{T}_{\mathrm{u}}$ & $\mathrm{T}_{\mathrm{u}} / 8$ \\
\hline
\end{tabular}

Table 2. PID parameters

\begin{tabular}{llll}
\hline PID Gains & $\mathrm{K}_{\mathrm{P}}$ & $\mathrm{T}_{\mathrm{I}}$ & $\mathrm{T}_{\mathrm{D}}$ \\
\hline Values & 44 & 0.0485 & 0.012 \\
\hline
\end{tabular}

\subsection{Comparison of Open Loop and Closed Loop System}

From the Fig. 7, it can be concluded that a PID Ziegler-Nichols method is suitable to design gain values for D.C. Motor, where the overshoot in the closed loop response is reduced to zero and steady state error is minimized.

\subsection{Four Quadrant Operation}

The D.C. motor is operated in four quadrant modes of torque-speed plane. At initial conditions, the motor is operated in forward motoring mode. When negative speed step signal command is issued, the machine undergoes braking operation in forward direction with speed tending to zero and motor starts rotating in reverse direction as soon as the speed is zero.

When a speed negative step signal command is issued again, the motor undergoes reverse braking and operates in forward motoring mode. The traverse path of the operating point under four quadrants operation commands are depicted in torque-speed characteristics as shown in Fig. 8.
In the Fig. 9 arrows indicate the travels of speedtorque curve from first quadrant (forward motoring) to third quadrant (reverse motoring) via second quadrant (forward braking) in four quadrants

The above Fig. 10-12 shows that the average motor voltage varies linearly with input signal .Also the D.C Motor voltage jumps between $+V_{d c}$ and $-V_{d c}$ so that this switching strategy is referred as the bipolar voltage switching.

It has to be noted that the duty ratio $\alpha_{1}$ can be varied between 0 and 1 , depending on the magnitude and polarity of the control voltage. Therefore $\mathrm{Vo}$ can be continuously varied in the range of $+V_{d c}$ to $-V_{d c}$, while motor current can be either positive or negative such that the motor can four quadrants of the Vo-Io plane

From Fig. 13 and 14 shows that total harmonics distortion of the supply line current is reduced to a great extent in the closed loop system when compared to open loop system.

\section{CONCLUSION}

The performance of single phase DC motor drive controlled by PID-PWM technique with bipolar voltage switching is investigated, with a view to improving the output torque, voltage, current and speed response characteristics .During the course of this study the open loop and closed response of DC motor drive were analyzed and simulation study was carried out using MATLAB/Simulink. The simulation results confirm that the PID controller delivers the better speed regulation of DC drives. The total harmonics distortion is reduced to $42.08 \%$ and reduced steady state error. Finally a speed controller has been designed successfully for closed loop 
four quadrant operation of the DC motor which runs very closed to the reference speed.

\section{REFERENCES}

Abdelhamid, T.H., 2000. Performance of single-phase DC drive system controlled by uniform PWM full-bridge DC-DC converter. Proceedings of the 10th Meditwranean Electrotechnical Conference, May 29-31, IEEE Xplore Press, pp: 974-977. DOI: $10.1109 /$ MELCON.2000.879695

Al-Mashakeh, A.S.O., 2009. Proportional integral and derivative control of brushless DC motor. Eur. J. Sci. Res., 35: 198-203.

Hamed, S.A., 1997. Performance evaluation of threephase variable-speed DC drive systems with uniform PWM control. IEEE Trans. Power Electron., 12: 228-242. DOI: 10.1109/63.558732

Hang, C.C., K.J. Astrom and W.K. Ho, 1991. Refinements of the Ziegler-Nichols tuning formula. IEE Proc. D Cont. Theory Applic., 138: 11-18.

Hui, S.Y.R., H.S.H. Chung and S.C. Yip, 2000. A bidirectional AC-DC power converter with power factor correction. IEEE Trans. Power Electron., 15: 942-949. DOI: 10.1109/63.867684

Kazmierkowski, M.P. and L. Malesani, 1998. Current control techniques for three-phase voltage-source PWM converters: A survey. IEEE Trans. Ind. Electron., 45: 691-703. DOI: 10.1109/41.720325

Krishnan, R., 2001. Electric Motor Drives: Modeling, Analysis and Control. 1st Edn., Prentice Hall PTR, Upper Saddle River, ISBN-10: 0130910147, pp: 626 .
Lin, B.R. and H.H. Lu, 2000. A novel PWM scheme for single-phase three-level power-factor-correction circuit. IEEE Trans. Ind. Electron., 47: 245-252. DOI: $10.1109 / 41.836339$

Mehra, V., S. Srivastava and P. Varshney, 2010. Fractionalorder PID controller design for speed control of DC motor. Proceedings of the 3rd International Conference on Emerging Trends in Engineering and Technology, Nov. 19-21, IEEE Xplore Press, Goa, pp: 422-425. DOI: 10.1109/ICETET.2010.123

Montiel, O., R. Sepulveda, P. Melin, O. Castillo and M.A. Porta et al., 2007. Performance of a simple tuned fuzzy controller and a PID controller on a DC motor. Proceedings of the IEEE Symposium on Foundations of Computational Intelligence, Apr. 1-5, IEEE Xplore Press, Honolulu, HI., pp: 531-537. DOI: 10.1109/FOCI.2007.371523

Thomas, N. and P. Poongod, 2009. Position control of DC motor using genetic algorithm based PID controller. Proceedings of the World Congress on Engineering, Jul. 1-3, London UK.

$\mathrm{Yu}$, G.R. and R.C. Hwang, 2004. Optimal PID speed control of brush less DC motors using LQR approach. Proceedings of the IEEE International Conference on Systems, Man and Cybernetics, Oct. 10-13, IEEE Xplroe Press, pp: 473-478. DOI: 10.1109/ICSMC.2004.1398343

Zhang, X.D., 2008. Simulation analysis on differential speed drive of double BLDCM based on PID. Proceedings of the 3rd International Conference on Innovative Computing Information and Control, Jun. 18-20, IEEE Xplore Press, Dalian, Liaoning, pp: 285-285. DOI: 10.1109/ICICIC.2008.494 